\title{
New evidence for enhanced ocean primary production triggered by tropical cyclone
}

\author{
I. Lin, ${ }^{1}$ W. Timothy Liu, ${ }^{2}$ Chun-Chieh Wu, ${ }^{3}$ George T. F. Wong, ${ }^{4}$ Chuanmin $\mathrm{Hu},{ }^{5}$ \\ Zhiqiang Chen, ${ }^{5}$ Wen-Der Liang, ${ }^{1}$ Yih Yang, ${ }^{1}$ and Kon-Kee Liu ${ }^{1}$ \\ Received 16 February 2003; accepted 14 May 2003; published 15 July 2003.
}

[1] New evidence based on recent satellite data is presented to provide a rare opportunity in quantifying the long-speculated contribution of tropical cyclones to enhance ocean primary production. In July 2000, moderate cyclone Kai-Tak passed over the South China Sea (SCS). During its short 3-day stay, Kai-Tak triggered an average 30-fold increase in surface chlorophyll-a concentration. The estimated carbon fixation resulting from this event alone is $0.8 \mathrm{Mt}$, or $2-4 \%$ of SCS's annual new production. Given an average of 14 cyclones passing over the SCS annually, we suggest the long-neglected contribution of tropical cyclones to SCS's annual new production may be as much as $20-30 \%$. INDEX TERMS: 4275 Oceanography: General: Remote sensing and electromagnetic processes (0689); 4805 Oceanography: Biological and Chemical: Biogeochemical cycles (1615); 0315 Atmospheric Composition and Structure: Biosphere/ atmosphere interactions; 4504 Oceanography: Physical: Air/sea interactions (0312); 1615 Global Change: Biogeochemical processes (4805). Citation: Lin, I., W. T. Liu, C.-C. Wu, G. T. F. Wong, C. Hu, Z. Chen, W.-D. Liang, Y. Yang, and K.-K. Liu, New evidence for enhanced ocean primary production triggered by tropical cyclone, Geophys. Res. Lett., 30(13), 1718, doi:10.1029/2003GL017141, 2003.

\section{Introduction}

[2] Tropical cyclones (also known as hurricanes or typhoons) when passing over land may have devastating effects on human lives, but over the ocean they can strongly enhance another form of life - ocean primary (phytoplankton) production. Ocean primary production plays significant roles in the earth environmental system. Besides being the base of the ocean food chain, half of the world's oxygen is produced by phytoplankton. Like all plants, phytoplankton uses carbon dioxide, sunlight and nutrients to photosynthesize and multiply. Thus, primary production also affects the uptake of carbon dioxide, an important greenhouse gas and a major cause of natural and man-made climate changes [Eppley and Peterson, 1979].

[3] Primary production takes place in the top 50 to $150 \mathrm{~m}$ of the water column (euphotic zone) where there is abundant light for photosynthesis. The supply of nutrients is

\footnotetext{
${ }^{1}$ National Center for Ocean Research, Taiwan.

${ }^{2}$ Jet Propulsion Laboratory, NASA, USA.

${ }^{3}$ Dept. of Atmospheric Sciences, National Taiwan University, Taiwan.

${ }^{4}$ Dept. of Ocean, Earth and Atmospheric Sciences, Old Dominion University, USA.

${ }^{5}$ College of Marine Sciences, Univ. of South Florida, USA.
}

mostly from the pumping of nutrient-rich deep water to the euphotic zone through various mechanisms. However, the traditionally accepted mechanisms are insufficient to explain the observed productivity [McGillicuddy and Robinson, 1997]. Consequently, there have been intensive searches for new pumping mechanisms to account for the observed unexplained production [McGillicuddy et al., 1998; Villareal et al., 1999; Uz et al., 2001]. New mechanisms ranging from mesoscale eddies [McGillicuddy et al., 1998] to Rossby waves [Uz et al., 2001] have been proposed. For long it has been speculated that tropical cyclones' strong wind may give rise to significant nutrient pumping, however, due to high observational difficulty, evidences were grossly deficient in quantifying this speculation [Eppley and Renger, 1988; Marra et al., 1990; Dickey et al., 1998]. Thus the contribution of tropical cyclones remains neglected in primary production estimation.

[4] The notion that the strong wind associated with tropical cyclones causes entrainment (vertical mixing) and upwelling [Price, 1981; Emanuel, 1999] in the tropical and subtropical oceans - whereby deep-layer cold, nutrient-rich water is brought to the light-replete euphotic zone to fuel photosynthetic activities and cause enhancement of primary production (phytoplankton bloom) - is not new [Eppley and Renger, 1988; Marra et al., 1990; Dickey et al., 1998]. However, documenting this biogeochemical response of the ocean to a passing tropical cyclone is not trivial. Tropical cyclones are transient, violent atmospheric processes with great variations in trajectory and strength. Thus, ship-borne observation on prescribed schedules and cruise tracks is not feasible and highly dangerous. Despite their high cost, in situ mooring arrays at several pre-determined locations are not feasible, either, owing to cyclones' great trajectory variations. Therefore, such responses are hardly, if ever, captured. Even if such a response is captured, the discrete point measurements by ship or mooring do not provide sufficient spatial coverage for quantitative estimation of the cycloneinduced phytoplankton bloom to primary production.

[5] Satellite remote sensing has the potential to overcome the above-mentioned constraint as measurements over large spatial domain, at frequent intervals, and under severe weather conditions, are possible. However, to observe such biogeochemical responses, a radiometer at visible and infrared frequencies (ocean colour sensor) has been employed. This type of sensor is obscured by clouds, which are often present during and after cyclone episodes. Therefore, very few events are captured by ocean colour remote sensor. In this study, we present a rare successful case whereby the bloom patch is partially captured by NASA's SeaWiFS (Seaviewing Wide Field-of-view Sensor) ocean colour sensor. More significant opportunities were provided by the incor- 

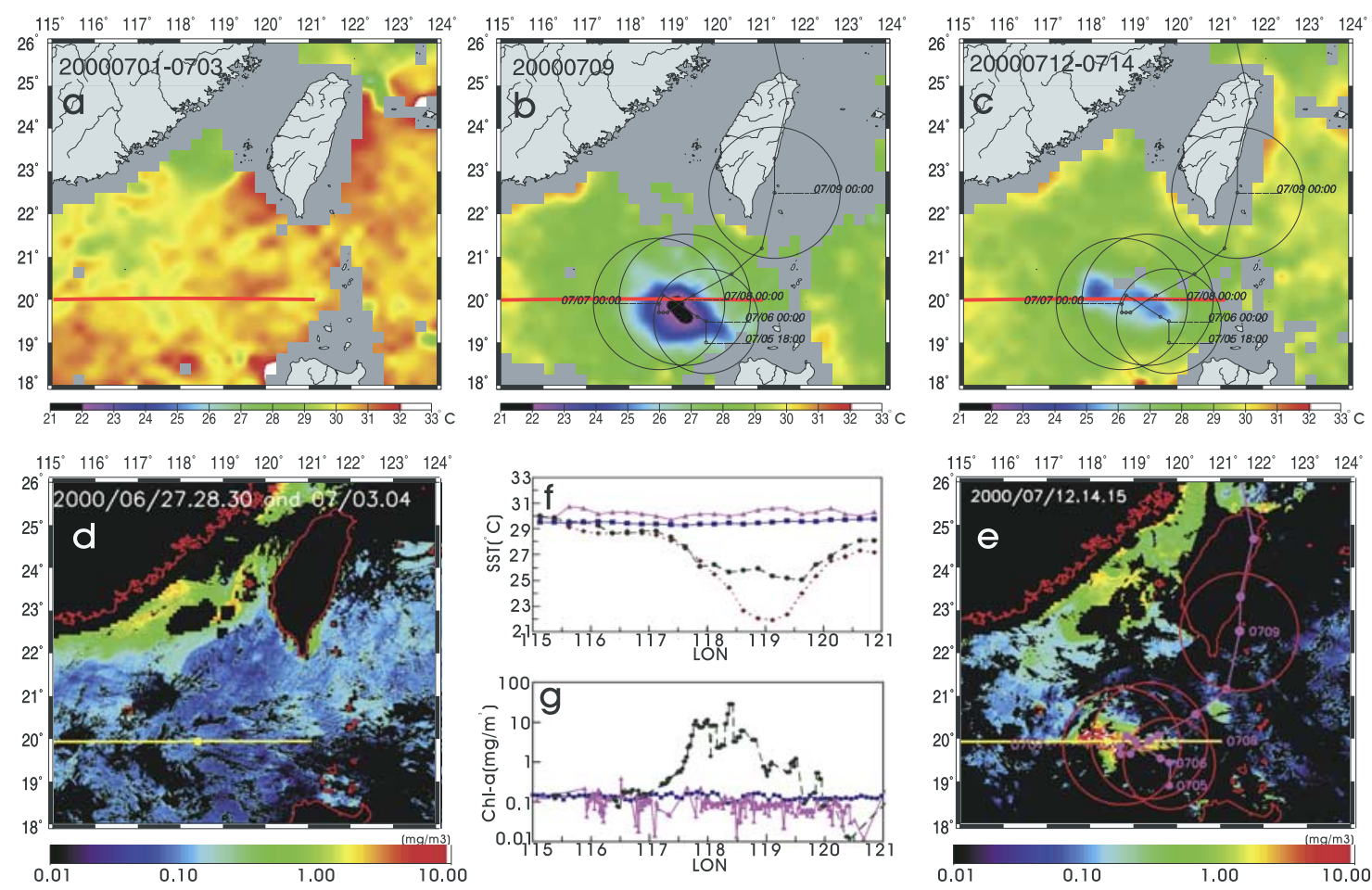

Figure 1. TRMM TMI/SST image on (a) 1-3 July 2000, before the arrival of typhoon Kai-Tak; (b) 9 July 2000, after typhoon Kai-Tak; (c) 12-14 July 2000, illustrating the match between cold SST pool (Figure 1c) and the bloom patch (Figure 1e). SeaWiFS surface Chl-a image composite on (d) 27 June-4 July 2000, before Kai-Tak; and (e) 12,14,15 July 2000, after Kai-Tak. The circle denotes Kai-Tak's RMW (Radius of Maximum Wind). The location of the transect tr1 is depicted as the red/yellow line crossing the longitude. (f) Comparison of the SST distribution along tr1. Pink: before, (from Figure 1a). Brown: after, (from Figure 1b). Green: after, (from Figure 1c) Blue: The 3-year (1998, 1999, 2001) climatological average of SST for July. (g) Comparison of the surface Chl-a distribution along tr1. Pink: before (from Figure 1d). Green: after, (from Figure 1e). Blue: The 3-year (1998, 1999, 2001) climatological average of surface Chl-a concentration for July.

poration of two microwave sensors, QuikSCAT, and Tropical Rainfall Measuring Mission (TRMM) Microwave Imager (TMI). They measure ocean surface wind vector (QuikSCAT) and sea surface temperature (TMI), under both clear and cloudy conditions, day and night. The cloudpenetrating capability of TMI allows the entire area of entrainment (location of the bloom patch) to be sensed, which greatly complements the partial coverage of the SeaWiFS sensor. Thus, the contribution of the entire bloom patch to the primary production can be estimated. QuikSCAT provides the wind forcing to drive a mixed-layer model to verify the observed thermal and biological responses.

[6] In the following paragraph, we will show that the three independent satellite (SeaWiFS, TRMM, QuikSCAT) observations and mixed-layer model output give a consistent explanation of the observed physical and biogeochemical responses induced by tropical cyclone Kai-Tak. The observational data is then input to a primary production model [Behrenfeld and Falkowski, 1997] to estimate the contribution of Kai-Tak to primary production.

\section{SST Response Induced by Tropical Cyclone Kai-Tak}

[7] Kai-Tak was a moderate category 2 typhoon in the Saffir-Simpson hurricane scale. It lingered at a near stationary slow speed $(0-1.4 \mathrm{~m} / \mathrm{s})$ on the northern South
China Sea (SCS) from 5 to 8 July 2000 before it proceeded speedily $(\approx 6.1 \mathrm{~m} / \mathrm{s})$ northwards thereafter (Figure 1) [Central Weather Bureau, Taiwan]. Before Kai-Tak's arrival, the SCS is characterised by warm SST predominantly above $30^{\circ} \mathrm{C}$ (Figure 1a). The wind speed was between 5 to $10 \mathrm{~m} / \mathrm{s}$. During 5-8 July, Kai-Tak's strong wind $(20-40 \mathrm{~m} / \mathrm{s})$ dominated the wind field (Figure 2). Immediately after Kai-Tak's departure, on 9 July, a cold SST $\left(21.5-24^{\circ} \mathrm{C}\right)$ pool $\left(118-120^{\circ} \mathrm{E}, 19-20.5^{\circ} \mathrm{N}\right)$ of size comparable to Kai-Tak's 150-km RMW (Radius of Maximum Wind) co-located with the typhoon's track was observed (Figure 1b). The minimum SST of $21.5^{\circ} \mathrm{C}$ was found at the centre $\left(118.9^{\circ} \mathrm{E}, 19.9^{\circ} \mathrm{N}\right)$ of the cold pool. In comparison with the pre-typhoon condition $\left(30.7^{\circ} \mathrm{C}\right)$, the SST dropped as much as $9^{\circ} \mathrm{C}$. How did such a drastic response happen? Entrainment mixing is in general the primary mechanism accounting for the SST response [Price, 1981]. However, for a slow-moving cyclone (translation speed $\leq 4 \mathrm{~m} / \mathrm{s}$ ), such as, Kai-Tak, strong upwelling occurs with entrainment and the response is significantly enhanced [Price, 1981]. Using QuikSCAT wind vectors, entrainmentinduced mixed-layer deepening estimated by a mixed-layer model [Price et al., 1986] was 90m. Strong upwelling, characterised by high pumping velocity of above $20 \times$ $10^{-4} \mathrm{~m} / \mathrm{s}$ (i.e., $100 \mathrm{~m}$ vertical displacement over half of the inertial period), at the cold pool location was also found (Figure 2). 


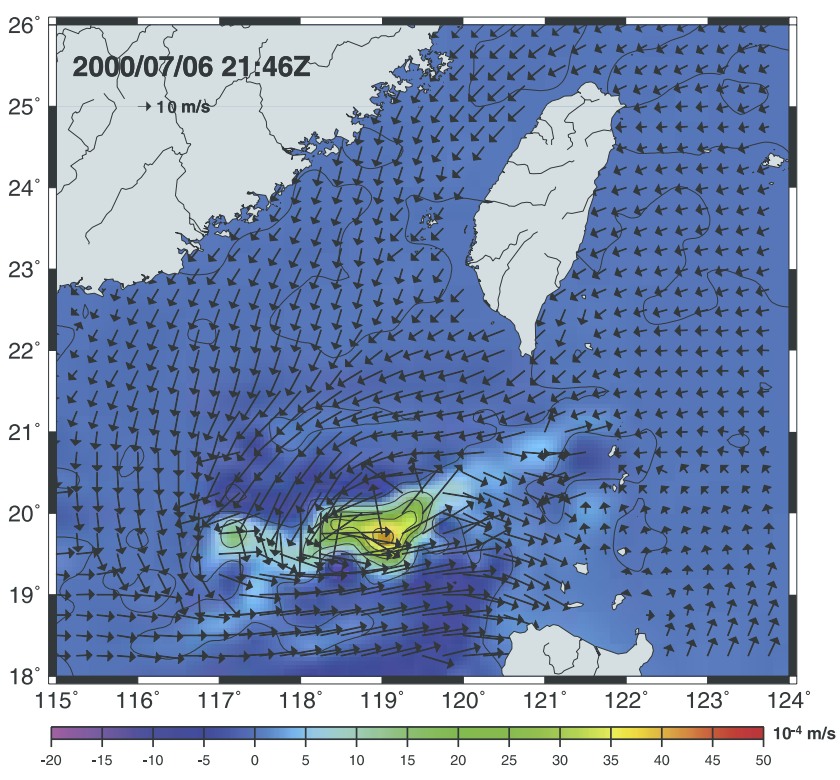

Figure 2. Vectors: QuikSCAT wind vectors at 21:46 UTC 6 July 2000 illustrating Kai-Tak's wind field, the wind speed is mostly between $20-40 \mathrm{~m} / \mathrm{s}$. Colours and contours: contours of the Ekman pumping velocity estimated from QuikSCAT wind vectors showing upwelling $\left(118-120^{\circ} \mathrm{E}\right.$, $19-20.5^{\circ} \mathrm{N}$ ) induced by Kai-Tak.

[8] The location, scale, and the peak of the upwelling (Figure 2) were well matched with the cold SST pool (Figure 1b). These results are consistent with the in situ hydrographic survey conducted outside the influence of the cyclone, at the South East Asia Time-Series (SEATS) station $\left(116^{\circ} \mathrm{E}, 18^{\circ} \mathrm{N}\right)$ on 25 July 2000 (Figure 3). The surface mixed layer, with a temperature of $29^{\circ} \mathrm{C}$, was only about $20-30 \mathrm{~m}$ deep. Temperature dropped to $21.6^{\circ} \mathrm{C}$, the minimum temperature in the cold pool, at $71 \mathrm{~m}$. The $90-\mathrm{m}$ deepening of mixed layer and high pumping velocity above $20 \times 10^{-4} \mathrm{~m} / \mathrm{s}$ during the passing of typhoon could readily transport the cold water from $70 \mathrm{~m}$ and below to the surface.

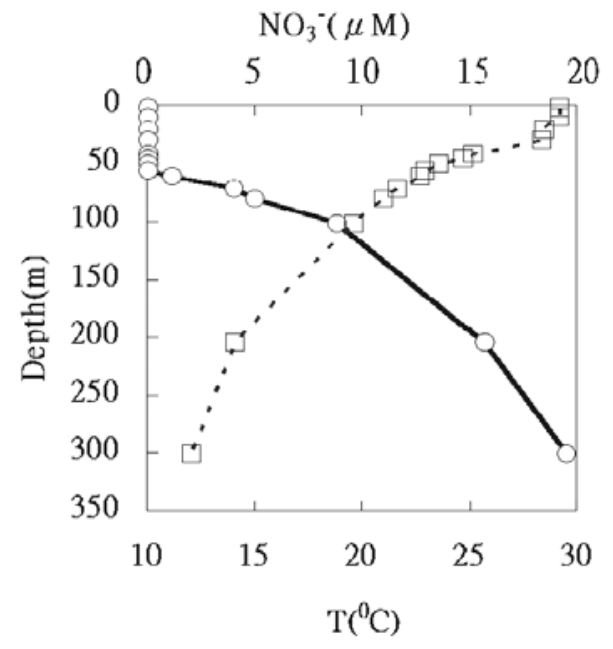

Figure 3. The in situ vertical profiles of nitrate (circle) and temperature (square) at the SEATS station $\left(116^{\circ} \mathrm{E}, 18^{\circ} \mathrm{N}\right)$ in the northern SCS on July 25, 2000.
By 12-14 July, this cold pool had slowly decayed but still maintained a low temperature of $25^{\circ} \mathrm{C}$ (Figure 1c). The distributions of SST along a transect, $\operatorname{tr} 1$ (location depicted in Figures 1a-1c), crossing through the cold pool before and after the passing of the typhoon together with the 3-year (1998, 1999, and 2001) climatological mean for July are shown in Figure 1f.

\section{Biological Response Induced by Tropical Cyclone Kai-Tak}

[9] The biological response of the SCS to the passing of Kai-Tak was depicted by changes in the surface distribution of Chl-a. The pre-typhoon condition was illustrated in the SeaWiFS composite from 27 June-4 July 2000 (Figure 1d) which showed the typical summer condition of surface Chl-a concentrations predominantly $\leq 0.1 \mathrm{mg} / \mathrm{m}^{3}$. After Kai-Tak's passage (5-8 July), the first available cloud free SeaWiFS image composite (12-15 July) illustrated a clear enhancement of biological activity (Figure 1e). The bloom patch $\left(117.5-120^{\circ} \mathrm{E}, 19.3-20.7^{\circ} \mathrm{N}\right.$, colour coded: yellow-red), of average surface Chl-a concentrations of $3.2 \pm 4.4 \mathrm{mg} / \mathrm{m}^{3}$, coincided with Kai-Tak's trajectory and its RMW, and the cold pool revealed by TMI (Figure 1c). At certain locations (e.g. $\left.118.4^{\circ} \mathrm{E}, 20^{\circ} \mathrm{N}\right)$, the Chl-a concentrations reached as high as $30 \mathrm{mg} / \mathrm{m}^{3}$, as depicted in the Chl-a distribution (in log scale) along tr1 (Figure 1g). The pre-typhoon (from Figure 1d) and the climatological (monthly average of July for the years 1998, 1999, and 2001) surface Chl-a concentrations along $\operatorname{tr} 1$ are also depicted for comparison. The in situ nutrient profile (Figure 3) illustrated the shallow nutricline at about 50m; though with undetectable concentrations of nitrate above the nutricline, sharp increase in nitrate concentration is found from $50 \mathrm{~m}$ and below. The combination of the mixed layer deepening (90m), high pumping velocity $\left(\geq 20 \times 10^{-4} \mathrm{~m} / \mathrm{s}\right)$, and shallow nutricline $(50 \mathrm{~m})$ could reasonably explain the pumping of sufficient nutrients to cause the observed bloom.

\section{Enhancement of Primary Production by Tropical Cyclone Kai-Tak}

[10] The changes in SST, surface Chl-a, and depthIntegrated Primary Production (IPP) with time at the bloom centre are shown in Figure 4. The temperature depression and the phytoplankton bloom, as indicated by the elevation of the surface Chl-a concentration, could be tracked for

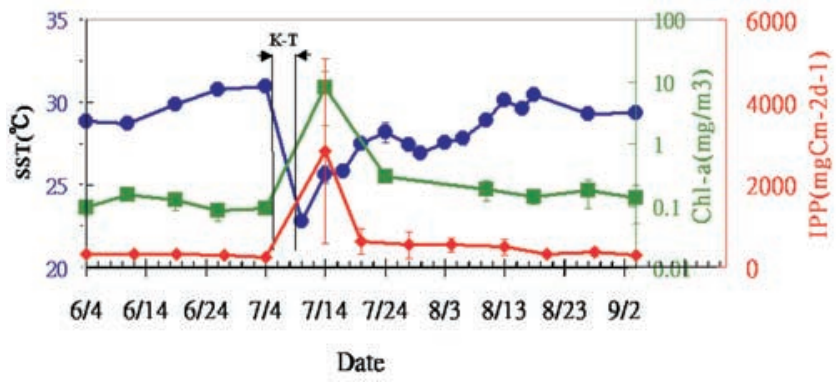

Figure 4. Changes in SST (blue), surface Chl-a (green, log scale), and IPP (red) of the bloom patch before and after Kai-Tak's passage (5-8 July). 
about 1 month. The corresponding IPP was estimated by applying the observed concentrations of surface Chl-a and SST to the relationship between the photo-adaptive variables and SST [Behrenfeld and Falkowski, 1997]. The pretyphoon IPP was $300 \mathrm{mgCm}^{-2} \mathrm{~d}^{-1}$, similar to the annual mean IPP of $350 \mathrm{mgCm}^{-2} d^{-1}$ [Liu et al., 2003]. Soon after the passage of the typhoon, IPP shot up to $2800 \mathrm{mgCm}^{-2} \mathrm{~d}^{-1}$. By integrating IPP over the bloom patch through each time interval, the carbon fixation resulting from this single event (12 July-16 August) was about $0.8 \mathrm{Mt}\left(1 \mathrm{Mt}=10^{12} \mathrm{~g}\right)$ of carbon. Taking the $200 \mathrm{~m}$ isobath as the boundary of the oligotrophic waters, the area of the oligotrophic SCS is $2.76 \times 10^{6} \mathrm{~km}^{2}$, or about $80 \%$ of the total area of the SCS. If the $f$ ratio in the SCS is similar to those in other oligotrophic waters, 0.06 to 0.14 [Eppley, 1989], this typhoon would have accounted for 2 to $4 \%$ of the annual new production in the oligotrophic SCS. This is a minimum estimation as IPP from 6 to 11 July, during and immediately after the passing of Kai-Tak, had not been included in the calculation because of the lack of cloud-free SeaWiFS data. SST image indicates that significant entrainment had already occurred on 9 July (Figure 1b).

\section{Conclusion}

[11] Due to the lack of quantitative evidence, the contribution of tropical cyclones to primary production has long been neglected. Our results, based on the synergy of three recent-available satellite data sets, provides a rare opportunity to quantify such a contribution. We found that Kai-Tak, a moderate tropical cyclone during its short 3-day stay, made a significant impact (i.e., on average 30-fold increase in surface chl-a concentration and $2-4 \%$ of SCS's annual new production) on the enhancement of primary production. Given that on average 14 cyclones traverse the SCS each year with a number of them of stronger intensity and longer duration than Kai-Tak, this leads us to suggest the contribution of tropical cyclones to SCS's annual new production may be as much as $20-30 \%$. Thus we dispel the currently accepted negligible contribution of tropical cyclones to the SCS's primary production, and instead present a case for its significance.

[12] Acknowledgments. We thank Prof. D.-P. Wang at the State University of New York, Stony Brook for assistance in mixed-layer model calculation, Prof. Werner Alpers at the University of Hamburg, Germany and Dr. Antony Liu at GSFC/NASA for constructive comments and discussions, Ms. Meggie Lien and Mr. Faye Pan for help in image processing. Thanks also to the QuikSCAT team, SeaWiFS team, and Remote Sensing Systems for data provision. I.I.L.'s work was supported by the National Science Council, Taiwan (projects: National Center for Ocean Research and NSC 91-2119-M-002-032). This paper is also an IMaRS contribution \#0060.

\section{References}

Behrenfeld, M. J., and P. G. Falkowski, Photosynthetic rates derived from satellite based chlorophyll concentration, Limnology and Oceanography, 42(1), 1-20, 1997.

Dickey, T., D. Frye, J. McNeil, D. Manov, N. Nelson, D. Sigurdson, H. Jannasch, D. Siegel, A. Michaels, and R. Johnson, Upper-ocean temperature response to Hurricane Felix as measured by the Bermuda Testbed Mooring, Mon. Wea. Rev., 126, 1195-1201, 1998.

Emanuel, K., Thermodynamic control of hurricane intensity, Nature, 401, 665-669, 1999.

Eppley, R. W., and B. J. Peterson, Particulate organic matter flux and planktonic new production in the deep ocean, Nature, 282, 677-680, 1979.

Eppley, R. W., and E. H. Renger, Nanomolar increase in surface layer nitrate concentration following a small wind event, Deep-Sea Res., 35, 1119-1125, 1988.

Eppley, R. W., New production: History, methods, problems. Productivity of the Ocean: Present and Past, edited by W. H. Berger, V. S. Smetacek, and G. Wefer, Wiley, Chichester, 85-97, 1989.

Liu, K.-K., S.-Y. Chao, P.-T. Shaw, G.-C. Gong, C.-C. Chen, and T.-Y. Tang, Monsoon-forced chlorophyll distribution and primary production in the South China Sea, Deep-Sea Res. Part I, in press, 2003.

Marra, J., R. R. Bidigare, and T. D. Dickey, Nutrients and mixing, chlorophyll and phytoplankton growth, Deep-Sea Res., 37, 127-143, 1990.

McGillicuddy, D. J., Jr., and A. R. Robinson, Eddy-induced nutrient supply and new production in the Sargasso Sea, Deep-Sea Res., I 44, $1427-$ 1450, 1997.

McGillicuddy, D. J., Jr., A. R. Robinson, D. A. Siegel, H. W. Jannasch, R. Johnson, T. D. Dickey, J. McNeil, A. F. Michaels, and A. H. Knap, Influence of mesoscale eddies on new production in the Sargasso Sea, Nature, 394, 263-265, 1998

Price, J. F., Upper ocean response to a hurricane, Journal of Physical Oceanography, 11, 153-175, 1981

Price, J. F., R. A. Weller, and R. Pinkel, Diurnal cycling: observations and models of the upper ocean response to diurnal heating, cooling, and wind mixing, J. Geophys. Res., 91, 8411-8427, 1986.

Uz, B. M., J. A. Yoder, and V. Osychny, Pumping of nutrients to ocean surface waters by the action of propagating planetary waves, Nature, 409, 597-600, 2001.

Villareal, T. A., C. Pilskain, M. Brzezinski, F. Lipschultz, M. Dennerr, and G. B. Gardner, Upward transport of oceanic nitrate by migrating diatom mats, Nature, 397, 423-425, 1999.

I. Lin, W.-D. Liang, Y. Yang, and K.-K. Liu, National Center for Ocean Research, P.O. Box 23-13, Taipei, 10617, Taiwan. (linii@ncor.ntu.edu.tw) W. T. Liu, Jet Propulsion Laboratory, California Institute of Technology, 4800 Oak Grove Drive, Pasadena, CA 91109, USA.

C.-C. Wu, Dept. of Atmospheric Sciences, National Taiwan University, Taiwan.

G. T. F. Wong, Department of Ocean, Earth and Atmospheric Sciences, Old Dominion University, Norfolk, VA 23529-0276, USA.

C. Hu and Z. Chen, College of Marine Sciences, University of South Florida, St. Petersburg, FL 33701, USA. 